\title{
Mechanism of Rural Entrepreneurship Development on the Base of Micro-business
}

\author{
Tatiana A. Zabaznova ${ }^{1}$, Svetlana E. Karpushova ${ }^{1}$, Elena V. Patsyuk ${ }^{1}$, Olga A. Surkova ${ }^{1}$ \& Galina A. Khmeleva ${ }^{2}$ \\ ${ }^{1}$ Sebryakovskiy branch of "Volgograd State University of architecture and civil engineering", Mikhaylovka, \\ Russia \\ ${ }^{2}$ Samara Academy of State and Municipal Management, Samara, Russia \\ Correspondence: Svetlana E. Karpushova, Michurina Street, 21, Mikhaylovka, Volgograd region, Russia. Tel: \\ 89-02-341-9377. E-mail: sfkse@yandex.ru
}

Received: August 1, 2014 Accepted: September 1, 2014 Online Published: November 14, 2014

doi:10.5539/ass.v10n23p168 URL: http://dx.doi.org/10.5539/ass.v10n23p168

\begin{abstract}
The author analyzes the essence of rural business development strategy, is a model of strategic management of agricultural entrepreneurship, and defines the basic components of the major actions to ensure the implementation of strategies for the development of agricultural entrepreneurship, aimed at selection of optimal directions and priorities of development of the territory. The author develops and justifies the mechanism of development of agricultural entrepreneurship, based on micro-businesses; it allocates system mechanisms for the implementation of strategies, and analyzes its key components. The author is an agricultural business model of motivation and mechanism of changes in strategy. The author defines the space program-target method in the mechanism of external control of strategic management of agribusiness takes application. The author defines the system of normative legal acts that have a logical connection and subordination and regulating the use of specific methods and tools of government regulation necessary for the successful combination of marked intra and external strategic activities for the development of agricultural entrepreneurship.
\end{abstract}

Keywords: rural entrepreneurship, development mechanism, micro-business, agricultural entrepreneurship

\section{Introduction}

Implementation of the strategy of development of agricultural business includes choosing the right combination of structure and control strategy implementation of enterprise structure. In general, the control is necessary because although the structure of management intends implementing roles and tasks, it does not provide their motivation. In recent decades, rural areas "cultivated" tradition of theft, drunkenness, etc. In connection with this control here is much more important management tool, than in urban areas.

System of strategic control systems are formal goal-setting control, monitoring, evaluation and feedback, which provide managers with information about the organization and the need for corrective action. Consequently, the control system must implement the four stages of action:

1) establishment of standards for evaluation of functioning, which should be developed concurrently with the strategy;

2) creation of a measuring system that will show the degree of achievement of the objectives, which is a complex task, since many actions are difficult to assess;

3) comparison of the actual functioning of the defined objectives;

4) evaluation and comparison of production, if necessary, corrective action.

\section{Method}

Evaluation and monitoring of the development strategy of rural enterprise are logically the final process ensuring a stable inverse relationship between the progress of the objectives and the actual goals.

Control problems in the subjects of agricultural entrepreneurship are of particular importance due to the following facts. The modern village is still strong dependency of the population, when any successful business is perceived quite hostile. As a result, cases deliberate damage to property owners. In addition, the employees 
themselves sometimes use business structures of new opportunities for theft, embezzlement, etc. In the regions with the most unfavorable socio-economic situation, this problem becomes significant scale.

On the other hand, rural entrepreneurs themselves insufficiently attentive to control financial flows of their organization, thereby reducing the efficiency of business.

In this connection, the main control tasks are as follows:

1) to determine what indicators to verify the functioning of a business entity;

2) assessment of the controlled object in accordance with accepted standards, regulations, or other benchmarks, including both tangible objects and managerial and organizational solutions;

3 ) determine the causes of deviations and losses, if any, shall be opened as a result of the evaluation;

4) Implementation of corrections, if necessary and possible.

Strategic control focuses on figuring out whether it is possible to further implement the strategy adopted enterprise development, and whether its implementation will lead to the desired goals. In other words, strategic control - is a subsystem of strategic management, which coordinates the functions of strategic analysis, goal setting, planning and compensation strategies; controls the operation of the whole system, as well as sets, develops and oversees the strategic subsystem Dataware. All these tasks are extremely important in the process of agricultural entrepreneurship.

The main functions of strategic control include:

1) monitoring the implementation of the overall strategy;

2) the establishment and development of a system of information support of strategic management;

3) monitoring system of strategic indicators / indices, including separately for external and internal environment;

4) The primary elemental and integral strategic analysis;

5) primary fixation critical strategic positions micro organizations (internal and external);

6) participate in the formulation of strategic objectives;

7) participation in the secondary strategic analysis and strategic reflection;

8) coordination of all phases of strategic management as a process and in general all the elements of strategic management as an organic system.

To strategic control system to be effective, it must satisfy a number of requirements. The most important requirements for the incoming information from the monitoring system are the following:

1) The information should be available in a timely manner so that you can take the necessary decisions to adjust the strategy;

2) the information must contain the correct data adequately reflect the state-controlled processes;

3) for information should indicate the exact time of its receipt, and the exact time to which it relates.

Strategic control system includes four main elements: the establishment of those indicators which will assess the implementation of the strategy, a system of measuring and monitoring the status of the control parameters, comparison of the actual state of the control parameters to their desired state, the evaluation result of the comparison and decision-making on adjustment.

The indicators, which will assess the implementation of the strategy, indicators are usually directly associated with that strategy is implemented.

Such groups of indicators are:

1) performance indicators;

2) indicators of human resources;

3) status indicators of the environment;

4) indicators characterizing house processes.

Selecting indicators for strategic control is in itself a task of strategic importance, as this will depend on assessment of a successful strategy. When selecting indicators for strategic control, management should arrange their priorities, in order to be able to make an unambiguous conclusion that if some indicators suggest that there are problems in the implementation of the chosen strategy, while others say that everything is fine. 
The second element of the strategic control is the creation of a system of measurement and monitoring the status of the control parameters, ie, monitoring implementation of the strategy. This is a very difficult task, since in many cases to measure them is not so easy. For example, serious difficulties arise when measuring integrated, synergistic effect. Often, the result of separate activities can be measured quite easily, and the addition of these results are not measurable.

The third element of the control system - a comparison of the actual state of the control parameters to their desired state. In conducting this comparison, managers may face three situations: the real state of higher (better) than desired, the real state corresponds to the desired and, finally, the real state of the desired worse.

The fourth and final element - the result of the comparison and evaluation of a decision on the adjustment. If the real state corresponds to the desired, usually a decision that no changes are necessary. In the case where the real state of the desired parameter control is better, you can increase the desired parameter control, but only under the condition that it would not be contrary to the purposes of the organization. When the real state of the control parameter below its desired state, it is necessary to identify the cause of the deviation and, if necessary, an adjustment in the behavior of the organization. This adjustment may concern as a means of achieving the objectives and the goals themselves.

Thus, strategic control as a target subsystem primarily assesses the progress of the overall strategy, the possibility and feasibility of further follow-defined strategy, the theoretically attainable through this strategy the main strategic goals.

\section{Results}

Implementation of the strategy through the development of programs, budgets and procedures that can be regarded as short-term and medium-term plans to implement the strategy. Basic components of the main actions to ensure the implementation of development strategies of agricultural entrepreneurship, aimed at selection of optimal directions and priorities areas are:

1) the main strategic goal;

2) strategic objectives;

3) strategic directions;

4) Main strategic objectives;

5) factors implement the strategic objectives;

6) tools implement the strategic objectives.

In Figure 2 presents the mechanism of development of agricultural entrepreneurship based on micro-business.

Realizability strategy laid at the design stage. For the strategy to work, it must be focused, differentiated, have a specific time horizon. Focused - stem from the objectives tree development strategies: mission and values, vision, vision implementation, cost objectives, material goals. Differentiated - aimed at achieving customer value target customer segments.

Systems implementation and control strategy are many, but the most effective and is used today is the balanced scorecard. Balanced Scorecard is a tool for strategic and operational management, which allows you to "bind" the strategic goals of business structure with business processes and everyday actions of employees at every level of government, as well as to monitor the implementation of the strategy. Thus, the balanced scorecard is a tool for implementing the strategy and not its development.

In rural areas the importance of the relationship strategy with the daily activities of business entities due to staff the need to reduce the extremely high risk business.

Balanced Scorecard as a strategic tool, characterized by the fact that all actions are interrelated business structure and have clear indicators that show how the plan is being implemented, at what rate is the achievement of objectives.

Balanced Scorecard links strategic outcomes and factors for achieving them, setting and tracking causal links between them. Most of the factors described in terms of achievement of non-financial indicators that are not recorded by conventional accounting systems, and if you are registered, it is not linked to the financial results. Thus, on the one hand, balanced scorecard management accounting expands the space, on the other, - accounting focuses on a limited set of the most informative for strategic evaluation indicators. 


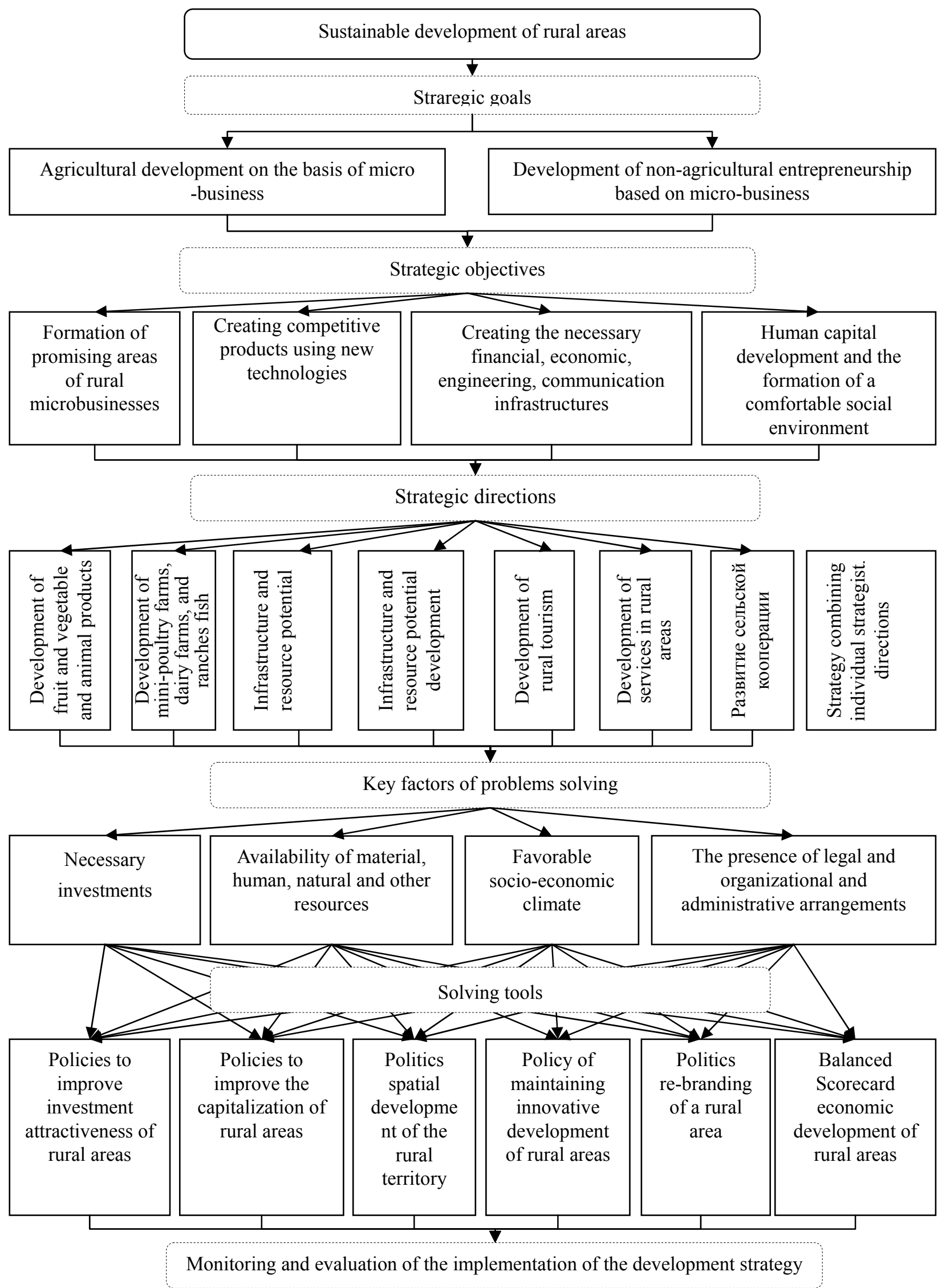

Figure 1. Mechanism of development of agricultural entrepreneurship based on micro-business 
From the perspective of the development of agricultural business advantages of this system include the ability to formalization fairly complex processes and phenomena which are not reflected in the financial statements of businesses. Unfortunately, at this time, in fact, conducting financial statements is the only quantitative tool for monitoring agricultural entrepreneurship. Strengthening the estimated component of management and decision-making will improve the efficiency of agricultural entrepreneurship, as the balanced scorecard allows you to translate strategy into specific objectives, strategic business objectives linked to the performance of each employee and properly motivate staff to implement the strategy as a result.

Thus, the problem of agricultural development on the basis of micro enterprises is to develop a system of management and control over the business structure that can ensure their implementation.

The main function of the development strategy of agricultural entrepreneurship is to provide work described herein mechanisms achieve management goals.

In practice, these mechanisms are so interrelated that it is difficult to single out any one component, "pure" nature, which would not contain the elements of the other components. Therefore, the system mechanisms formed on the principle of homogeneity, based on the main features of, in particular, organizational, economic and motivational (Figure 3).

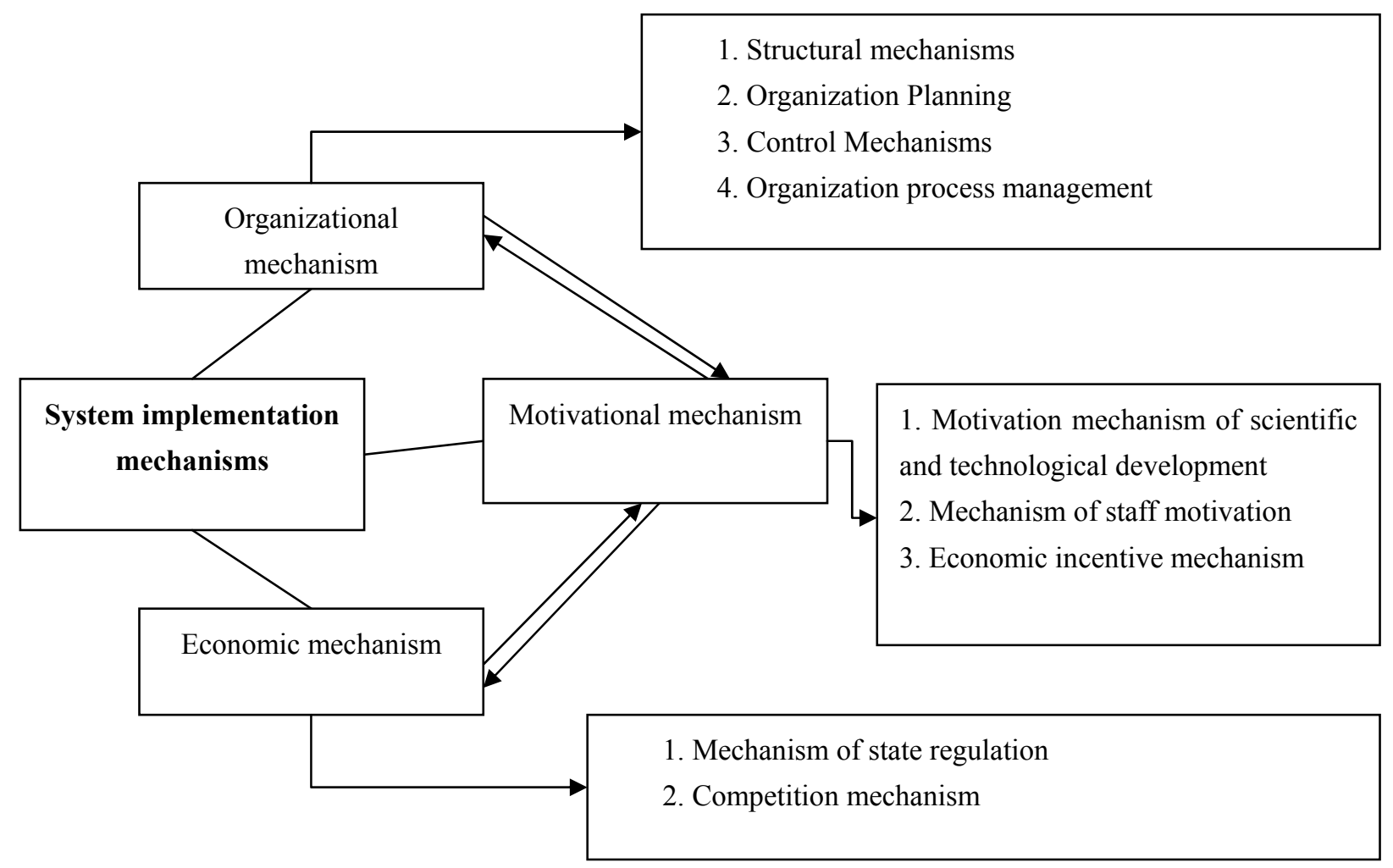

Figure 2. System mechanisms for implementing strategies (Shumilova, 2008)

The main mission of the organizational mechanism as part of a comprehensive framework for the development of rural business is to find new opportunities, and to ensure their competitive advantage through business areas. Term institutional mechanism means the combination of differentiated organizational and structural arrangements, with the interests of the organization's management in the long term, in the face of changing needs and unstable environment.

In the subjects of agricultural entrepreneurship institutional mechanisms focused mainly on the implementation of short-term tasks with virtually no long-term strategic orientation.

In order to form a holistic institutional mechanism are four main elements:

1. Structural mechanisms that address issues of modeling the structure of activities (diversification or specialization) of agricultural businesses; market structure and strategic areas of management. This issue is 
extremely important in rural areas, because in recent years many business entities faced with the problem of overproduction of some agricultural products and other deficits (Al-Dhaafri et al., 2014).

2. Organization planning and management, which is one of the main tasks of strategic management. In the planning and management of such areas can be identified functional activities such as strategic and operational planning, the formation of strategic policies and programs, business planning and budgeting. Honors strategic and operational planning are those deadlines or other problems. As the strategic objectives smoothly flow in the last stage of tactical solutions, and more - into the solution of operational problems. Current and strategic objectives in the agricultural business should be closely linked. Overexploitation of land, pastures, fisheries, forests, etc. without proper restoration leads to the degradation of the area economy and the inability of the business up to a few decades.

3. Control mechanisms may include all types of controls used in strategic management in the management cycle. Monitoring is necessary at the stage of development of business development strategies of the subject, and during its implementation and analysis. Parent diagnosis reveals reserves and possibilities of a business entity with strategic management, identify areas of internal adaptation capabilities of enterprise structure to changes in the external environment. As already indicated, the control in modern rural areas is a key deterrent to theft, increase productivity, and behavioral change of the rural population.

4. Organization of technical and technological management includes management standards and standards of production processes. This enables the design of these processes by creating a uniform regulatory organizational and technical basis of specialization and cooperation of production, ensure quality norms and standards, to intensify the introduction of new techniques and technologies to ensure safe working conditions, product certification, consumer protection, etc. In particular, talking about the introduction of advanced technologies of cultivation, irrigation, use of cultivated high quality materials, highly productive breeds of animals, etc.

Economic mechanism of development of agricultural enterprises should be based on the needs of business in the calculation of own and borrowed financial resources to achieve the goals of the strategy. Economy of rural areas in Russia is in a deplorable state, and therefore the increased attention to financial issues is a prerequisite for the successful development of entrepreneurship in them (Peng \& Li, 2014).

It seems appropriate to identify the following components of the economic mechanism:

1. Mechanism of competition due to the predicted results of the analysis of market conditions on the possible markets, taking into account the expected competitive strategies participants of market relations to the external environment. Hypercompetition grain products in the markets and the lack of animal products can serve as benchmarks for the development of agribusiness. However, not all entrepreneurs (in fact, most of them) analyze the evolving market situation to make decisions about their choice of directions of entrepreneurship. This is typical for representatives of microbusinesses.

2. Mechanism of state regulation of agricultural entrepreneurship should be aimed at promoting business and investment activity of business structures. To this end, a number of strategic initiatives planned by the Ministry of Agriculture of the Russian Federation, however, until the effect of the recent adoption of the relevant legislation is not scheduled to real change in the economy of rural areas.

Motivational mechanism is one of the components of the mechanisms of development of agricultural entrepreneurship. The term "motivational mechanism" means a collection of motives used in the implementation of the strategy to achieve strategic objectives, which are aimed at one or another set of motives.

In order to form a holistic mechanism of motivation necessary to consider three main elements:

1. Motivation mechanism of scientific and technological development of production includes the motivation of innovation and profit. The degree of implementation of the mechanism in organizations may be different depending on the level of competition in the markets for goods and technologies, demand for products and technology, the life cycle of technology and products, the degree of deterioration of the equipment, etc. In this case it is the entrepreneurs who are often guided agricultural technologies and products of the last century, slowly introduce innovations in agricultural activities (Kuppusamy \& Gharleghi, 2014).

2. Mechanism motivation. Targeting motivation development of personnel management is seen in the rational use of internal resources of the organization, increasing productivity, improving product competitiveness and therefore the market value of business structure. In this case, the key components of motivation should be financial incentives, as living standards in rural areas is low and it is a major cause of population migration from the countryside. 
3. Economic incentive mechanism differs from the motivation of personnel management higher his social status, that is, this is the motivation provided in management organization. The main motives of management is the introduction of advanced market innovations, which increases the competitiveness of business structure and thereby increases the market value of the organization. Motivation management in rural areas is possible in the process of raising the level of economic education senior management businesses. At the time, many entrepreneurs in rural areas do not own economic knowledge in amounts sufficient for effective business. Of course, sometimes it implies a significant investment of cash that cannot always afford the representatives of microbusinesses. Therefore, in this aspect is also important role of the State providing for micro enterprise structures opportunities for innovation on concessional or even grant terms. Agribusiness model of motivation is shown in Figure 4.

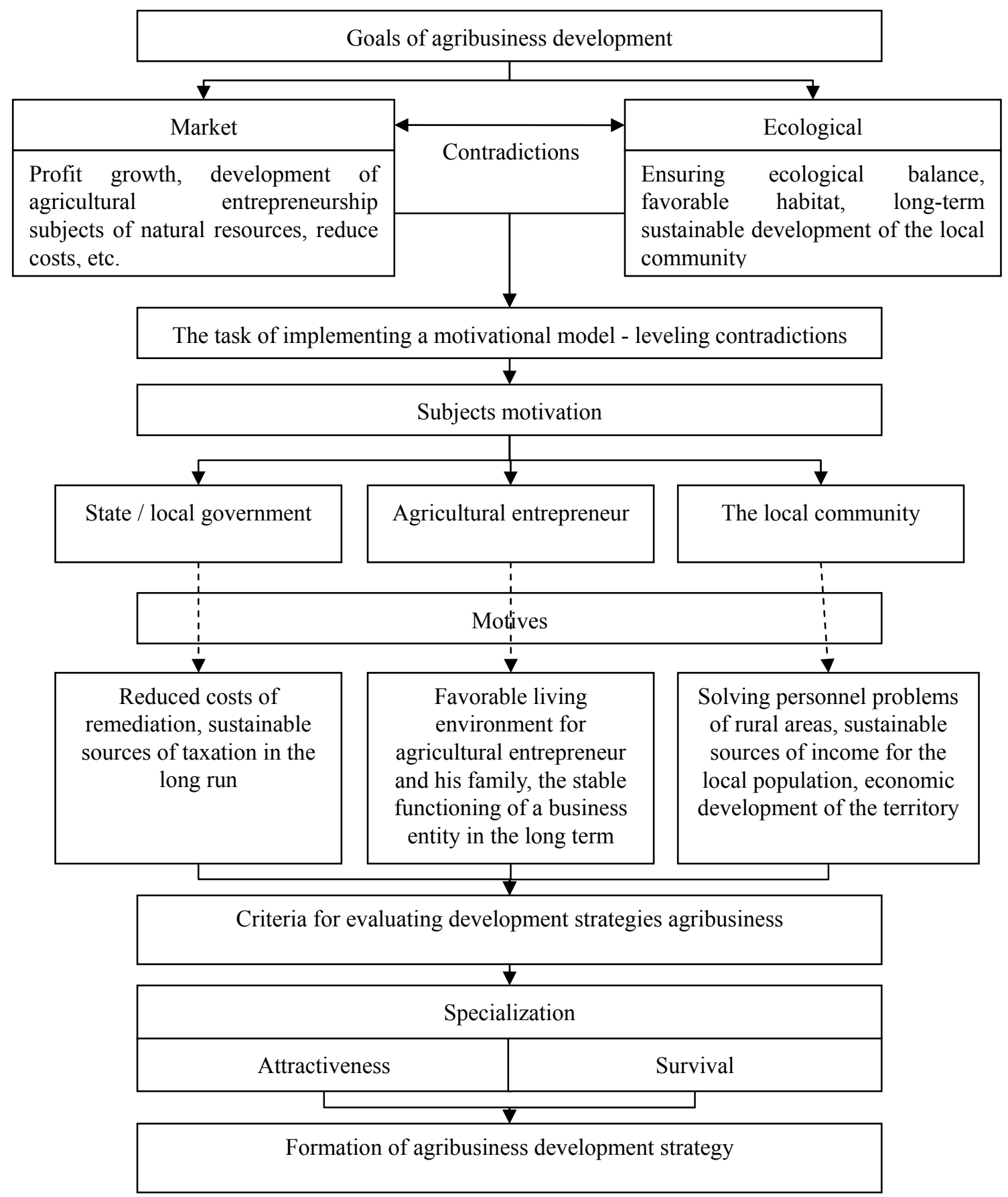

Figure 3. Model motivation agribusiness 
Mechanisms developed in the framework of an optimal strategy of development of agricultural businesses should have the property of integrity and, at the same time, rational detachment of its elements. This means that a change in any element of the mechanisms should lead to some changes in the changes in other mechanisms. For example, industry restructuring leads to changes in the number and composition of the lines of business, affects the interests of a large number of workers. At the same time, due to this you can get a new, more flexible and mobile structure, actively respond to changing market conditions.

\section{Discussion}

Thus, all of the proposed mechanisms should be included in a single system of external strategic management of sustainable development of agricultural entrepreneurship is at the state level as elements of the overall management system of rural areas.

Institutionalize the status of strategic documents, in which should be adopted a series of legislative acts ("The strategic planning", "The monitoring of indicators of socio-economic development" and other regulations at the local level), establishing procedures for planning, provides for the formation:

1) long-term strategy of development of business and the economy of rural areas as a whole;

2) medium-term socio-economic development, including a number of budget programs and quantitative indicators of their performance, as well as agreed with the limits of funding within the MTEF;

3) annual action plans;

4) reports (by activity and the synthesis) about the results and main activities of municipalities in rural areas.

External part of the operational and strategic planning should be policies and programs of socio-economic development of rural areas. Currently, strategic planning mainly covered only large cities and regions, while the rural areas do not pay attention to this issue. Moreover, those rural areas, who have decided on the implementation of certain activities of strategic planning, approach it very superficially, limited to a statement of the well-known problems and offering viable solutions for the development of the rural economy (Smallbone, 2005).

The main objectives of the Commission are: approval of the list of programs and projects to be implemented within the framework of the strategy; appraisal of the implementation of the main priorities of the development of agricultural businesses; synchronization implementation of key activities, programs and projects; consideration of proposals structural units of local government, public and scientific organizations, the business community to mainstream sustainable development of rural areas of the territory; correction (development of proposals for changes) the main activities and projects implementation.

Need to adjust the strategy associated with the rapidly changing external context of development of the region, which includes the change of federal policy with respect to the strategic directions of development of rural areas, changes in the foreign policy situation of the Russian Federation, the change in market conditions for the specialization of the Russian Federation and rural areas (drop / growth center in the world markets the emergence of new promising markets, the emergence of new competitors in Russia or other countries, etc.).

The mechanism of changes in strategy should be as follows:

1) semiannually interdepartmental commission coordinating the implementation of the strategy, generates a report based on monitoring the implementation of the strategy "on the implementation of the strategy";

2) according to a report introduced the proposals for changes in strategy;

3 ) in the case of a positive decision changes are made to the strategy.

A special place in the mechanism of external strategic management of agribusiness takes application program-target method of management, the use of which requires compliance programs set strategic goals and objectives, as well as the orientation of the existing targeted programs on the sustainable development of rural areas. In this case, rural areas interested in attracting regional and federal funds should develop adequate justification for the means and calculate their potential effectiveness in terms of entrepreneurship and its impact on the economy of rural areas in general. This step is necessary because many small municipalities in rural areas face acute shortage of funds due to the lack of significant objects of taxation and low entrepreneurial activity.

Necessary actions for the implementation of external strategic management of agricultural enterprises is its comprehensive public debate and inform the business community and the public about the goals, objectives and priorities of the strategy and mechanisms for achieving them, the decisions and actions taken by economic agents to implement the strategy, progress and results of implementation strategy and the effectiveness of decisions. 
Monitoring allows you to analyze the influence of various factors on the implementation of measures for the development of agricultural businesses. The combination of strategic and operational planning is a preliminary decision-making to achieve the desired results in the future that will allow for the organization and control of the system of key indicators of economic entities, the transition from rigid planning flexible response to changing conditions (Boateng, 2012).

Ability to adjust the mechanism of external strategic management of agricultural enterprises depending on changes in the state of internal and external environment is possible by adjusting the target programs of rural territory.

For a successful combination of in-house and external identified strategic actions for the development of agricultural businesses need to establish a system of regulations, having a logical connection and subordination and regulating the use of specific methods and tools of government regulation, consists of the following components:

1) development of medium-term socio-economic development of rural areas, determining the development of promising business areas of the territory;

2) development of sectoral strategies of rural areas;

Develop medium-term strategies and programs should be conducted with broad involvement of business community in rural areas. Since the level of development of rural business in Russia is very weak, the organization of such interaction does not present any difficulties. It is even possible to attract $100 \%$ of businesses in a particular rural area.

\section{References}

Al-Dhaafri, H. S., Yusoff, R. Z. B., \& Al-Swidi, A. K. (2014). The Relationship between Enterprise Resource Planning, Total Quality Management, Organizational Excellence, and Organizational Performance-the Mediating Role of Total Quality Management and Organizational Excellence. Asian Social Science, 10(14), 158-178.

Allen, J., \& Dillman, D. (1994). Against all the Odds: Rural Communities in the Information Age. Westview Press, Boulder.

Anderson, A., \& McAuley, A. (1999). Marketing Landscapes: The Social Context. Qualitative Marketing Research, 2(3), 176-188. http://dx.doi.org/10.1108/13522759910291680

Audretsch, D., \& Thurik, D. (2000). What's New about the New Economy? Sources of Growth in the Managed and Entrepreneurial Economies. Discussion paper, Tinbergen Institute, Erasmus University, Rotterdam.

Barkema, A., \& Drabescott, M. (2000). "How Rural America sees its Future”, The Main Street Economist. Federal Reserve Bank of Kansas City, Kansas City.

Beggs, J., Haines, V., \& Hurlbert, J. (1996). Revisiting the Rural-Urban Contrast: Personal Networks in Non-metropolitan and Metropolitan Settings. Rural Sociology, 61(2), 306-325. http://dx.doi.org/10.1111/j.1549-0831.1996.tb00622.x

Bennett, R. J., Bratton, W. A., \& Robson, P. (2000). Business Advice: The Influence of Distance. Regional Studies, 34(9), 813-828. http://dx.doi.org/10.1080/00343400020002958

Bennett, R., \& Smith, C. (2002), Competitive Conditions, Competitive Advantage and the Location of SMEs. Journal of Small Business and Enterprise Development, 9(1), 73-86. http://dx.doi.org/10.1108/146260002 10419509

Boateng, N. A. (2012). Promoting rural enterprise growth and development: Lessons from four projects in sub-Saharan Africa. International Fund for Agricultural Development, Italy.

Cameron, A., \& de Vries, H. (2006). The Role of Farmers Markets in Stimulating Rural Entrepreneurship: A Case Study of Felding Farmers Market. New Zealand, paper presented at the ICSB World Congress, Melbourne, 18-21 June.

Dabson, B. (2006). Promoting Rural Entrepreneurship, in OECD, Entrepreneurship in the Districts Uckermark in Brandenburg, and Parchim in Mecklenburg-Western Pomerania. Discussion Paper, OECD, Paris.

Kuppusamy, M., \& Gharleghi, B. (2014). Green Barriers and China's Agricultural Product Export: Is There Any Relationship? Asian Social Science, 10(16), 34-41. http://dx.doi.org/10.5539/ass.v10n16p34

Peng, O., \& Li, M. (2014). The Social Management Innovation of “Two Dimensional Four Points" and "The 
Trinity"-Based on the Example of Chongqing Rural Human Resources Development. Asian Social Science, 10(10), 219-225. http://dx.doi.org/10.5539/ass.v10n10p219

Shumilova, A. V. (2008). Mechanisms of implementation strategy of the organization. Problems of modern economics, 1(17), 25-29.

Smallbone, D. (2005). Fostering entrepreneurship in rural areas. Discussion Paper, OECD, UK.

\section{Copyrights}

Copyright for this article is retained by the author(s), with first publication rights granted to the journal.

This is an open-access article distributed under the terms and conditions of the Creative Commons Attribution license (http://creativecommons.org/licenses/by/3.0/). 